\title{
Investigations on mix design of tungsten mine waste geopolymeric binder
}

\author{
Fernando Pacheco-Torgal $^{\text {a,* }}$, J.P. Castro-Gomes ${ }^{\text {b,1 }}$, Said Jalali ${ }^{\text {c,2 }}$ \\ ${ }^{a}$ Castelo Branco Polytechnic Institute, Department of Civil Engineering, 6000 Castelo Branco, Portugal \\ ${ }^{\mathrm{b}}$ University of Beira Interior, Department of Civil Engineering, 6200 Covilhã, Portugal \\ ${ }^{\mathrm{c}}$ University of Minho, Department of Civil Engineering, 4800 Guimarães, Portugal
}

Received 18 January 2007; accepted 12 July 2007

Available online 4 September 2007

\begin{abstract}
Strength data show that the parameters, which lead to optimum strength for 7 days curing, remain the same for long curing ages. However, when calcium hydroxide percentages above $10 \%$ are used, strength decrease after 14th curing day is noticed. In order to explain this behaviour several hypotheses are discussed. The use of an activator with a sodium hydroxide concentration of $24 \mathrm{M}$ leads to a compressive strength of almost $70 \mathrm{MPa}$. The strength performance is typical of a very reactive binder, being suggested that it is due to the calcium hydroxide and also to the nucleation centers provided by the iron oxide of the mine waste mud. Results allow foreseeing that even higher strength performance could be achieved if lower water/sodium molar ratios were used.
\end{abstract}

(c) 2007 Elsevier Ltd. All rights reserved.

Keywords: Mix design; Geopolymeric binder; Tungsten mine waste; Compressive strength

\section{Introduction}

International commitments under Kyoto Protocol, related to greenhouse gas reductions [1,2], led to an increasing boost in the developing of construction materials with low $\mathrm{CO}_{2}$ emissions. Portland cement is the most used material in the construction industry worldwide, it has a high level of $\mathrm{CO}_{2}$ emissions ( 1 ton of cement generates 1 ton of $\mathrm{CO}_{2}$ ) and its use tends to become less competitive when compared to alternative ecological new binders [3]. Alkaliactivated binders based on industrial by-products such as fly ash and blast furnace slag represent a greener alternative to ordinary Portland cement due to their low $\mathrm{CO}_{2}$ emissions [4]. Furthermore, alkali-activated cementitious systems possessing very good chemical resistance $[5,6]$, and can be used as fireproof building materials [7], as protective

\footnotetext{
* Corresponding author. Tel.: +351272 339300; fax: +351272339399.

E-mail addresses: fernandotorgal@est.ipcb.pt (F. Pacheco-Torgal), castro.gomes@ubi.pt (J.P. Castro-Gomes), said@civil.uminho.pt (S. Jalali).

${ }^{1}$ Tel.: +351 275 329990; fax: +351 275329969 .

2 Tel.: +351 253 510204; fax: +351253510217.
}

coating for concrete surfaces [8] and to immobilize toxic metals with long term stability [9-11].

The alkali-activation of alumino-silicate waste materials is a complex chemical process evolving dissolution of raw materials, transportation or orientation and polycondensation of the reaction products. Some authors [12] mentioned the existence of two different models of alkali-activation. The first one is the alkali-activation of blast furnace slag (silicon and calcium) in which $\mathrm{C}-\mathrm{S}-\mathrm{H}$ is believed to be the main reaction process. In the case of the second model, the alkaline activation of metakaolin (silicon and aluminium) with high alkaline solutions yielding polymeric bonds can be taken as an example. Previous studies concerning the alkali-activation of different minerals suggest that a wide range of $\mathrm{Al}-\mathrm{Si}$ based minerals could be used as primary materials [13]. However, it must be noted that studies have used highly pure materials so far and it is expected that mine waste mineral will hardly behave just like them.

Previous studies, concerning the alkali-activation of tungsten mine waste mortars together with a small percentage of calcium hydroxide, suggest that a geopolymeric binder with extremely high early age strength can be produced $[14,15]$. 
The present work studies the joint effect of several parameters that could influence strength development with curing time, such as calcium hydroxide percentage, sodium hydroxide concentration and waterglass/sodium hydroxide mass ratio.

\section{Experimental work}

\subsection{Materials}

Tungsten mine waste mud used in this study was subject to a thermal treatment at $950{ }^{\circ} \mathrm{C}$ during 2 hours. Mineralogical composition and thermal conditions were described elsewhere [16]. The XRD patterns indicate that mine waste mud is composed mainly of muscovite and quartz which were identified by their characteristic patterns as follows: muscovite (card 46-1409) and quartz (card 46-1045). For those thermal conditions XRD patterns indicate that dehydroxylation did not result in a complete collapse of muscovite structure. Calcination results in a formation of an amorphous phase causing an increased general background (BG) in XRD patterns and dominantly taking place in the calcinations interval from 850 to $950{ }^{\circ} \mathrm{C}$ with a thermal behaviour similar to other phyllosilicate clay minerals. The main muscovite peak $\left(2 \theta=8.8^{\circ}\right)$ persisted even after the sample had been heated at $950^{\circ} \mathrm{C}$, although it diminished considerably. Peak area measurements reveal that about $12 \%$ of muscovite survived calcination at $950{ }^{\circ} \mathrm{C}$. Molecular changes during dehydroxylation were also examined with infrared emission confirmed by the diminishing absorption peaks at 3600-3700 (OH stretch); however, the peak does not disappear totally, indicating only a partial transformation.

The chemical composition and specific surface of the mine waste mud are shown in Table 1.

The fine aggregate used was a crushed sand from the same mine with a specific gravity of $2.7,24 \mathrm{~h}$ water absorption of $0.9 \%$, and a fineness modulus of 2.8 .

\subsection{Mixture operations and compressive strength testing}

The factors considered in this investigation led to the manufacture of several mixes. Distilled water was used to

Table 1

Chemical composition and specific surface

\begin{tabular}{lc}
\hline Constituents (\%) & Mine waste mud \\
\hline $\mathrm{SiO}_{2}$ & 53.48 \\
$\mathrm{Al}_{2} \mathrm{O}_{3}$ & 16.66 \\
$\mathrm{Fe}_{2} \mathrm{O}_{3}$ & 12.33 \\
$\mathrm{~K}_{2} \mathrm{O}$ & 7.65 \\
$\mathrm{Na}_{2} \mathrm{O}$ & 0.62 \\
$\mathrm{MgO}$ & 1.27 \\
$\mathrm{SO}_{4}$ & 3.10 \\
$\mathrm{TiO}_{2}$ & 1.39 \\
$\mathrm{As}$ & 1.28 \\
Other minor oxides & 2.22 \\
Blaine fineness $\left(\mathrm{m}^{2} / \mathrm{kg}\right)$ & 357 \\
\hline
\end{tabular}

dissolve the sodium hydroxide flakes to avoid the effect of unknown contaminants in the mixing water. The alkaline activator was prepared prior to use. The sand, mine waste mud and calcium hydroxide were dry mixed before adding the activator. To produce a workable mix extra water was added, and the mass ratio of water/dry solid content was $4 \%$.

Compressive strength data were obtained using $50 \times$ $50 \times 50 \mathrm{~mm}^{3}$ cubic specimens according to ASTM C109. The fresh mortar was cast and allowed to set at room temperature for $24 \mathrm{~h}$ before being removed from the moulds and kept at room temperature for another 6 days until tested in compression. Compressive strength for each mortar mixture was obtained from an average of 3 cubic specimens.

\section{Results and discussion}

\subsection{Influence of $\mathrm{Ca}(\mathrm{OH})_{2}$ and sodium hydroxide concentrations}

For a waterglass/sodium hydroxide mass ratio of 2.5:1, a set of mixtures were made containing several calcium hydroxide percentages $(10 \%, 15 \%, 17.5 \%, 20 \%$ and $22.5 \%$ ) and with sodium hydroxide concentrations from $6 \mathrm{M}$ to $16 \mathrm{M}$ (Table 2).

Fig. 1 shows compressive strength versus sodium hydroxide concentration according to calcium hydroxide percentage. The mortar mixtures with a $10 \%$ calcium hydroxide percentage present the maximum compressive strength, almost $30 \mathrm{MPa}$, for a sodium hydroxide concentration of $16 \mathrm{M}$ (to which corresponds an $\mathrm{H}_{2} \mathrm{O} / \mathrm{Na}_{2} \mathrm{O}$ molar ratio of 13.4). These results confirm the ones already obtained for early age compressive strength [15].

The mixtures, in which calcium hydroxide percentage is higher than $10 \%$, show strength decrease after 14 days curing. This strength loss related behavior is confirmed by others [18]. According to these authors, who studied alkali-activated metakaolin/slag mixtures, the maximum compressive strength has been achieved for a percentage

Table 2

Mortar composition (C105-C116)

\begin{tabular}{llllll}
\hline Compound & $\begin{array}{l}\text { Concentrated } \\
\text { Hydróxide }\end{array}$ & $\begin{array}{l}\text { Waterglass: } \\
\text { hydroxide }\end{array}$ & $\begin{array}{l}\mathrm{Ms} \\
\text { (sílica } \\
\text { modulus) }\end{array}$ & $\begin{array}{l}\mathrm{H}_{2} \mathrm{O} / \\
\mathrm{Na}_{2} \mathrm{O} \\
\text { molar } \\
\text { ratio }\end{array}$ & $\begin{array}{l}\text { Calcium } \\
\text { hydroxide } \\
(\%)\end{array}$ \\
\hline $\mathrm{C} 105$ & $16 \mathrm{M}$ & $2.5: 1$ & 1.34 & 13.7 & 17.5 \\
$\mathrm{C} 106$ & & & & 13.9 & 22.5 \\
$\mathrm{C} 107$ & $14 \mathrm{M}$ & & 1.41 & 14.3 & 17.5 \\
$\mathrm{C} 108$ & & & 14.6 & 22.5 \\
$\mathrm{C} 109$ & $12 \mathrm{M}$ & & 1.49 & 15.1 & 17.5 \\
$\mathrm{C} 110$ & & & 15.3 & 22.5 \\
$\mathrm{C} 111$ & $10 \mathrm{M}$ & & 1.59 & 16.0 & 17.5 \\
$\mathrm{C} 112$ & & & 16.3 & 22.5 \\
$\mathrm{C} 113$ & $8 \mathrm{M}$ & & 1.72 & 17.2 & 17.5 \\
$\mathrm{C} 114$ & & & 17.5 & 22.5 \\
$\mathrm{C} 115$ & $6 \mathrm{M}$ & & 1.90 & 18.7 & 17.5 \\
$\mathrm{C} 116$ & & & & 19.1 & 22.5 \\
\hline
\end{tabular}



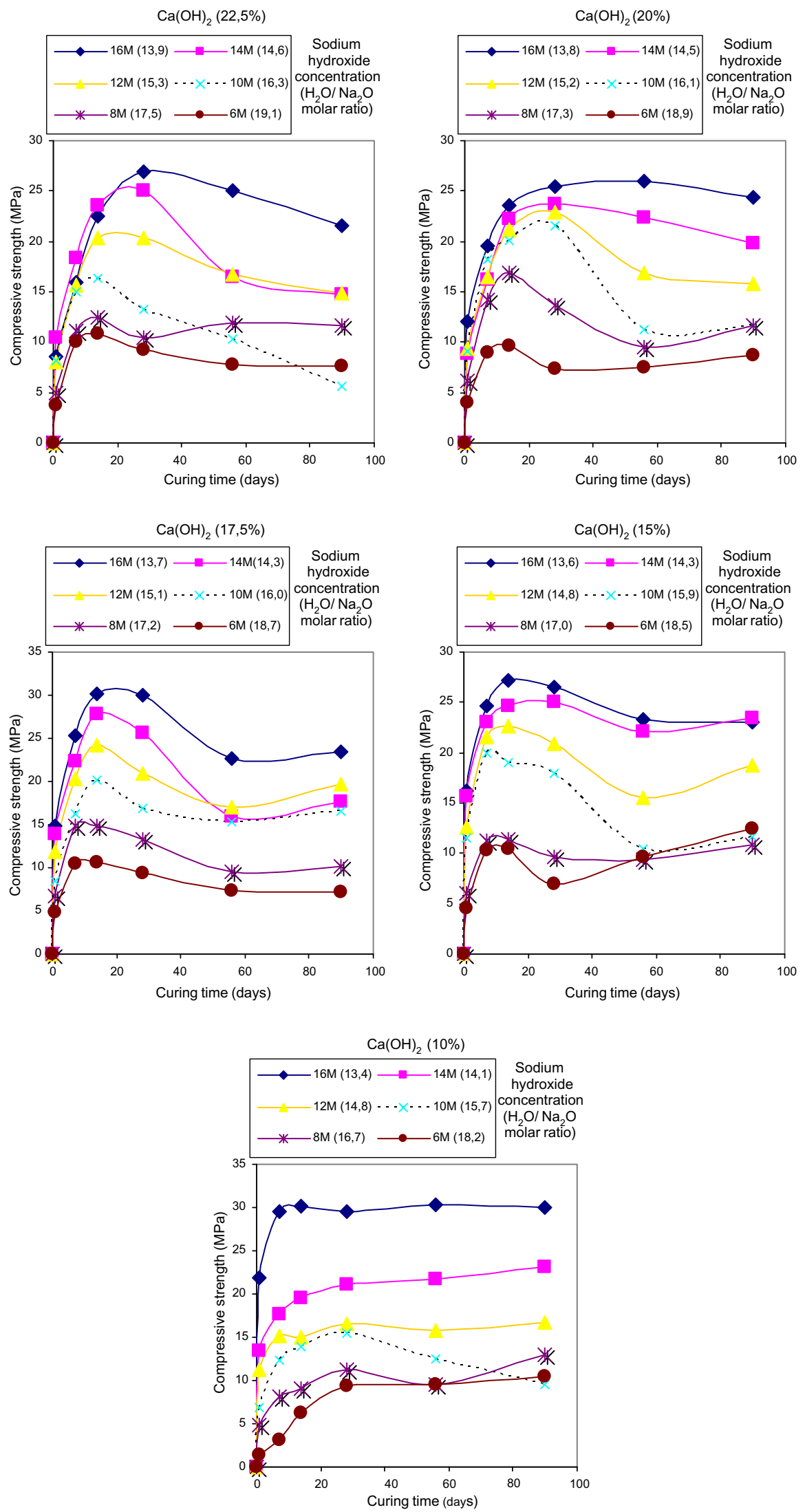

Fig. 1. Compressive strength versus sodium hydroxide concentration according to calcium hydroxide percentage $(22,5 \% ; 20 \% ; 17,5 \% ; 15 \%$ and $10 \%$ ). 
of $20 \%$ of slag (which corresponds to a calcium oxide content of $8.6 \%$ ). The explanation for this is related to the formation of two different phases, geopolymeric gel and calcium silicate hydrates, and the former acts as microaggregates [17].

However, when high slag percentages are used, for instance $40 \%$ of slag ( $17 \%$ calcium oxide), compressive strength decreases when curing time goes from 7 to 14 days curing. These authors believe that strength loss with curing time, is probably due to the fact that $\mathrm{CSH}$ reaction and the geopolymeric reaction will compete against each other for soluble silicates, gives rise to a binder composed of two porous phases which leads to strength loss.

An alternative explanation is related to the possibility of the occurrence of shrinkage cracking near the aggregates, originating a clear tensile strength reduction, which could only be confirmed when shrinkage and tensile strength were studied. And a third explanation is related to the formation of gel similar to the one that takes place in ASR of portland cement binders, so the gel volume increase would explain strength loss.

Fig. 2 shows compressive strength versus $\mathrm{H}_{2} \mathrm{O} / \mathrm{Na}_{2} \mathrm{O}$ molar ratio, for several calcium hydroxide percentages according to curing time. The results show a compressive strength increase with the $\mathrm{H}_{2} \mathrm{O} / \mathrm{Na}_{2} \mathrm{O}$ molar ratio decrease. It is more clear for mixtures with a $10 \%$ calcium hydroxide percentage a $\mathrm{H}_{2} \mathrm{O} / \mathrm{Na}_{2} \mathrm{O}$ molar ratio lower than 15 and higher curing ages. The rest of the mixtures with higher calcium hydroxide percentages sometimes show a strength increase for $\mathrm{H}_{2} \mathrm{O} / \mathrm{Na}_{2} \mathrm{O}$ molar ratio decrease, and that
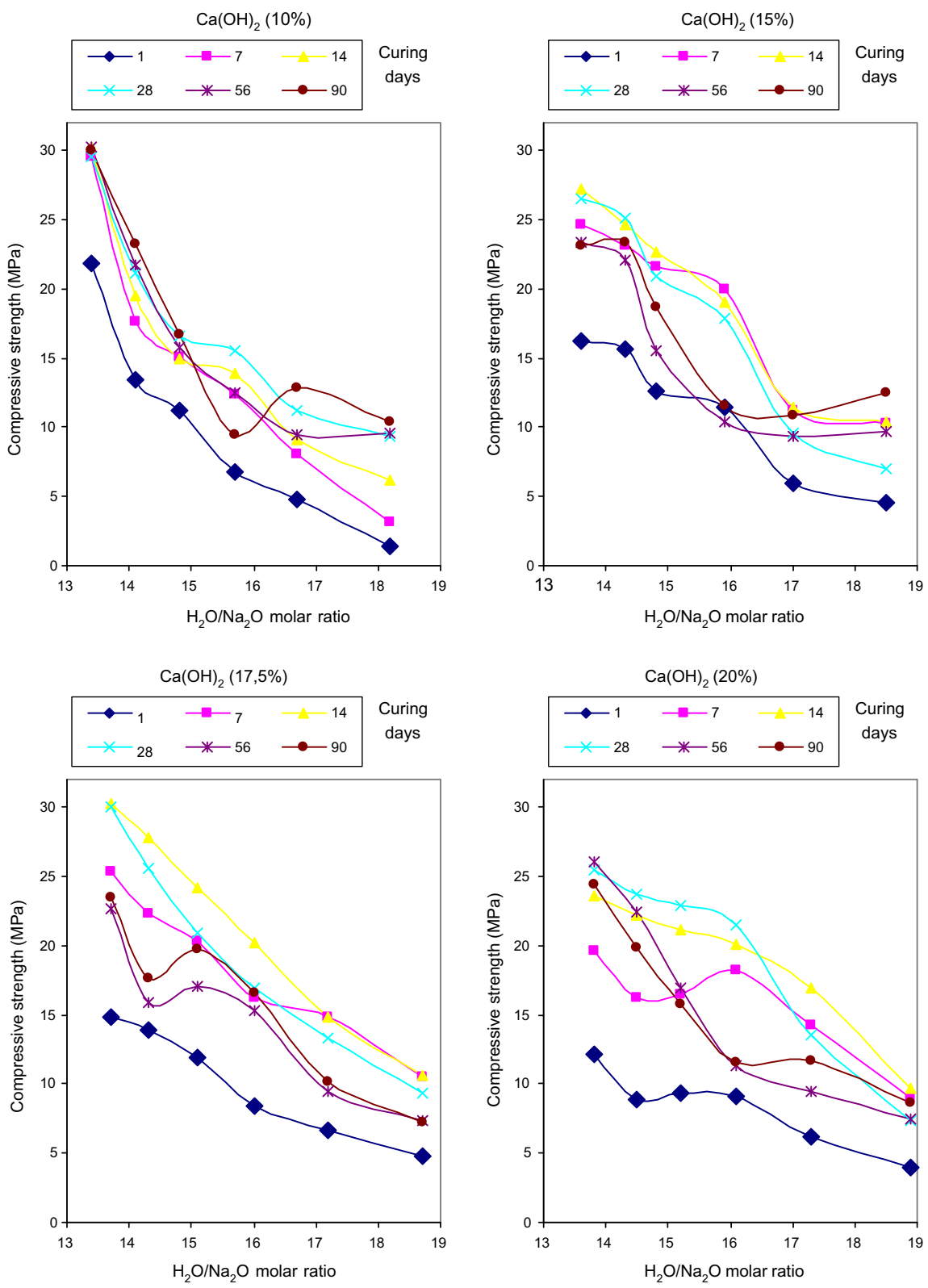

Fig. 2. Compressive strength versus $\mathrm{H}_{2} \mathrm{O} / \mathrm{Na}_{2} \mathrm{O}$ molar ratio according to calcium hydroxide concentration $(10 \%, 15 \%, 17.5 \%$ and $20 \%)$. 
occurs starts after 14 days curing. However, sometimes they also present a strength decrease when $\mathrm{H}_{2} \mathrm{O} / \mathrm{Na}_{2} \mathrm{O}$ molar ratio decreases. This behaviour has to do with calcium hydroxide solubility in high alkaline environment and with the formation of calcium hydroxide and $\mathrm{NSCH}$ precipitates. Therefore, it seems that higher compressive strength results could be expected for lower $\mathrm{H}_{2} \mathrm{O} / \mathrm{Na}_{2} \mathrm{O}$ molar ratios.

Table 3

Mortar composition (C117-C125)

\begin{tabular}{llllll}
\hline Compound & Concentrated hydróxide & Waterglass: hydroxide & Ms (sílica modulus) & $\mathrm{H}_{2} \mathrm{O} / \mathrm{Na}_{2} \mathrm{O}$ Molar ratio & Calcium hydroxide (\%) \\
\hline C117 & $16 \mathrm{M}$ & $4: 1$ & 1.54 & 15.2 & 20 \\
$\mathrm{C} 118$ & & 1.72 & 15.8 & \\
$\mathrm{C} 119$ & $6: 1$ & 1.86 & 16.3 & 14.9 & 15 \\
$\mathrm{C} 120$ & $4: 1$ & 1.54 & 14.7 & 10 \\
$\mathrm{C} 121$ & $4: 1$ & 1.54 & 14.5 & 5 \\
$\mathrm{C} 122$ & $4: 1$ & 1.54 & 15.5 & 15 \\
$\mathrm{C} 123$ & & $5: 1$ & 1.72 & 15.3 & 10 \\
C124 & & $5: 1$ & 1.72 & 15.0 & 5 \\
C125 & 5.1 & 1.72 & & \\
\hline
\end{tabular}
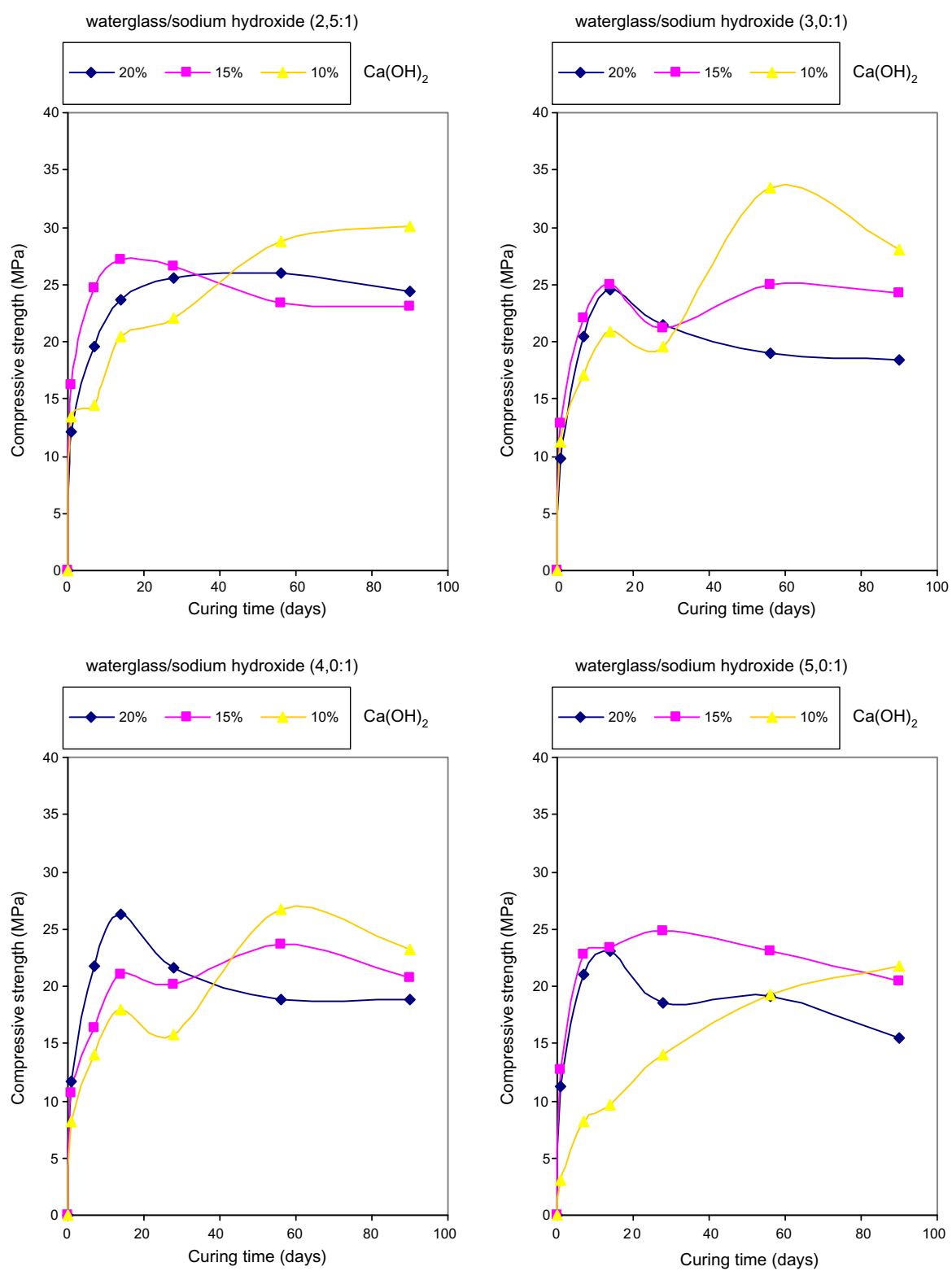

Fig. 3. Compressive strength according to curing time for several calcium hydroxide percentages and waterglass/sodium hydroxide mass ratios. 


\subsection{Influence of waterglass/sodium hydroxide mass ratio}

To confirm if the optimum waterglass/sodium hydroxide mass ratio of 2, 5:1, which was obtained for 7 days curing, does not change with curing age, several mixtures were studied, Table 3 presents some information related to these mixtures.
Figs. 3 and 4 show the compressive strength results according to curing age. The strength results due to the waterglass/sodium hydroxide mass ratio of $6: 1$ are not presented, because their low workability prevented mixing and placement operations. The results confirm that a waterglass/sodium hydroxide mass ratio of 2,5:1, associated to a calcium hydroxide percentage of $10 \%$, leads to the highest
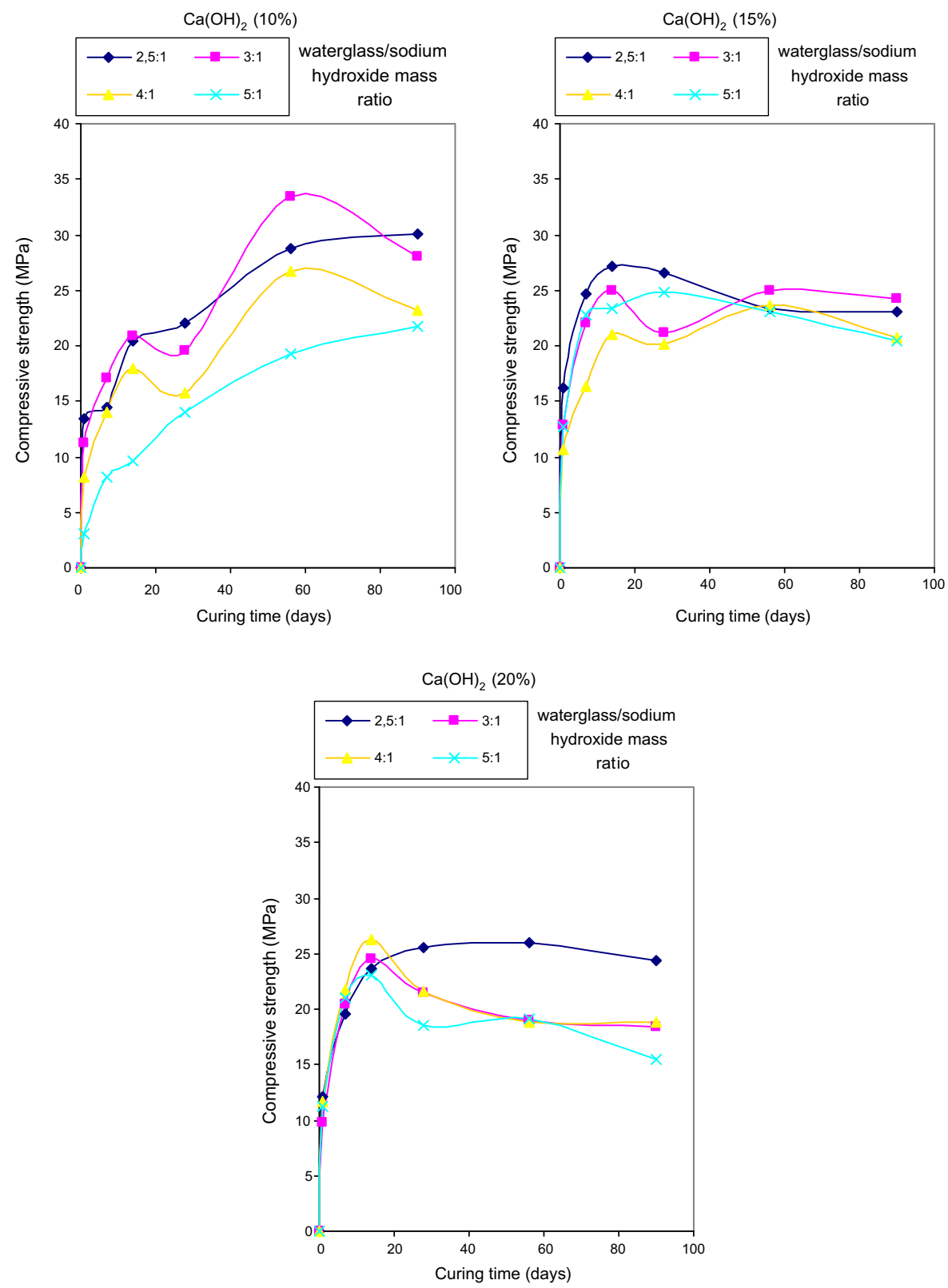

Fig. 4. Compressive strength according to curing time for several calcium hydroxide percentages and waterglass/sodium hydroxide mass ratios.

Table 4

Mortar composition (C126-C128)

\begin{tabular}{llllll}
\hline Compound & Concentrated hydróxide & Waterglass: hydroxide & Ms (sílica modulus) & $\mathrm{H}_{2} \mathrm{O} / \mathrm{Na}_{2} \mathrm{O}$ Molar ratio & Calcium hydroxide (\%) \\
\hline $\mathrm{C} 126$ & $24 \mathrm{M}$ & $2,5: 1$ & 1,17 & 10,3 & 10 \\
$\mathrm{C} 127$ & & & 10,7 & 25 \\
$\mathrm{C} 128$ & & & 10,2 & 5 \\
\hline
\end{tabular}


compressive strength. It was also noticed that the waterglass/sodium hydroxide mass ratio and therefore, the amount of soluble silica in the mixture are influenced by the amount of calcium hydroxide also present in the mixture. For a calcium hydroxide percentage of $10 \%$, increasing waterglass leads to strength decrease for 14 days curing and in a more pronounced form for 56 days. For calcium hydroxide percentages of $15 \%$ and $20 \%$ the strength loss occurs for 14 days curing. When the amount of waterglass present in the mixture is raised, strength results present a random behaviour, which could be due to the fact that more waterglass means less workable mixtures and thus more porous and with lower strength.

\subsection{Influence of $\mathrm{H}_{2} \mathrm{O} / \mathrm{Na}_{2} \mathrm{O}$ molar ratio}

Aiming to study the influence of the water/sodium mass ratio in strength increase, three nem mixtures have been made having a sodium hydroxide concentration of $24 \mathrm{M}$ (Table 4).

The option for this kind of concentration was due to the fact that it was the maximum concentration possible, because, although attempts have been made to synthesize a $25 \mathrm{M}$ sodium hydroxide concentration they reveal to be due to the fact that sodium pellets were not completely dissolved.

However, after noticing that the use of less aggregates means less extra water and thus a lower water/sodium mass ratio, it was decided to use an aggregate/binder mass ratio of 1 . After several previous mixes it was found that the extra water needed to properly mix and place the specimens is about $1.8 \%$ over the aggregate and binder mass. Fig. 5 shows compressive strength according to curing age. The results show a major strength increase, with $30 \mathrm{MPa}$ after just 1 day, reaching almost $70 \mathrm{MPa}$ after 28 days curing. This performance is mainly related to the use of less
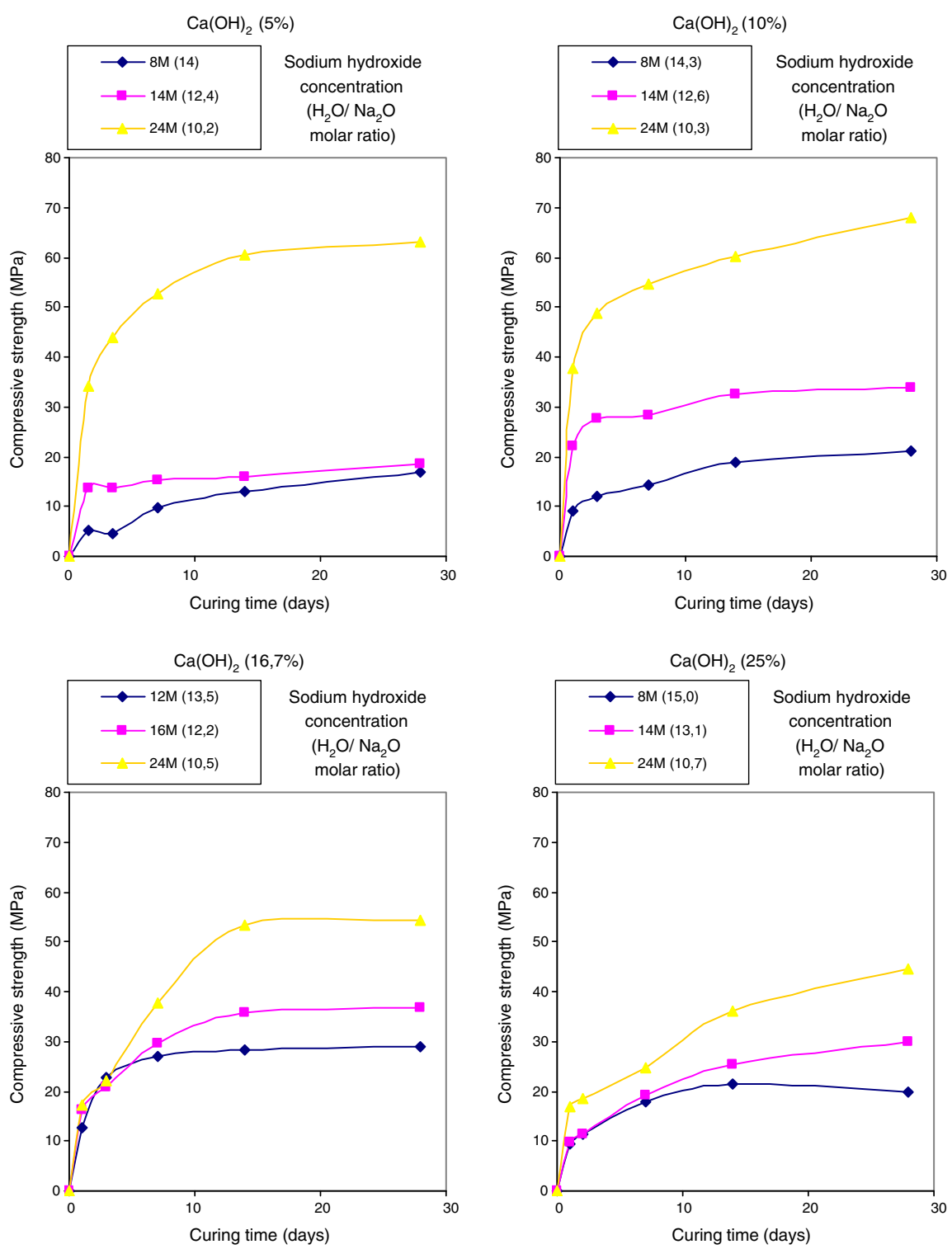

Fig. 5. Compressive strength according to curing time for several calcium hydroxide percentages and waterglass/sodium hydroxide mass ratios. 
aggregates and thus less extra water. The use of mixtures containing $5 \%$ of calcium hydroxide leads to lower strength after long curing time ages than when $10 \%$ calcium hydroxide mixtures were used. The strength differences are much higher for the initial curing days: after just 1 day the mixtures with $5 \%$ calcium hydroxide have just half the strength of the $10 \%$ calcium hydroxide mixtures.

The extraordinary strength increase is due to the use of a low $\mathrm{H}_{2} \mathrm{O} / \mathrm{Na}_{2} \mathrm{O}$ molar ratio, which influences strength development. When the alkaline concentration raises, which implies a higher amount of dissolved aluminosilicate species, more cementitious material is available to react. In the previous section it was reported that, with the exception of the composition with $10 \%$ calcium hydroxide all the others showed a strength decrease after 14 days curing, but now only the mixture with $25 \%$ calcium hydroxide and $8 \mathrm{M}$ concentration shows a strength decrease with curing time.
The adverse effect reported by others [18] related to reduction in strength due to excess of alkali has not been confirmed. It's thought that it must be a subject related to setting rate, because faster rates give less time for dissolution leading to more unreacted particles and strength reduction, so it may be expected that these authors used more reactive material (fly ash and kaolin) than mine waste mud used in the present work.

Results show that compressive strength is influenced by the percentage of calcium hydroxide, and the highest strength is achieved for a $10 \%$ calcium hydroxide percentage. However, the use of a $5 \%$ calcium hydroxide percentage leads to similar strength results for long curing ages. This means that for this mixing conditions compressive strength is not so much influenced by calcium hydroxide percentage. An explanation for such behaviour may rely on the fact that aluminosilicate (geopolymeric) compounds are being formed.
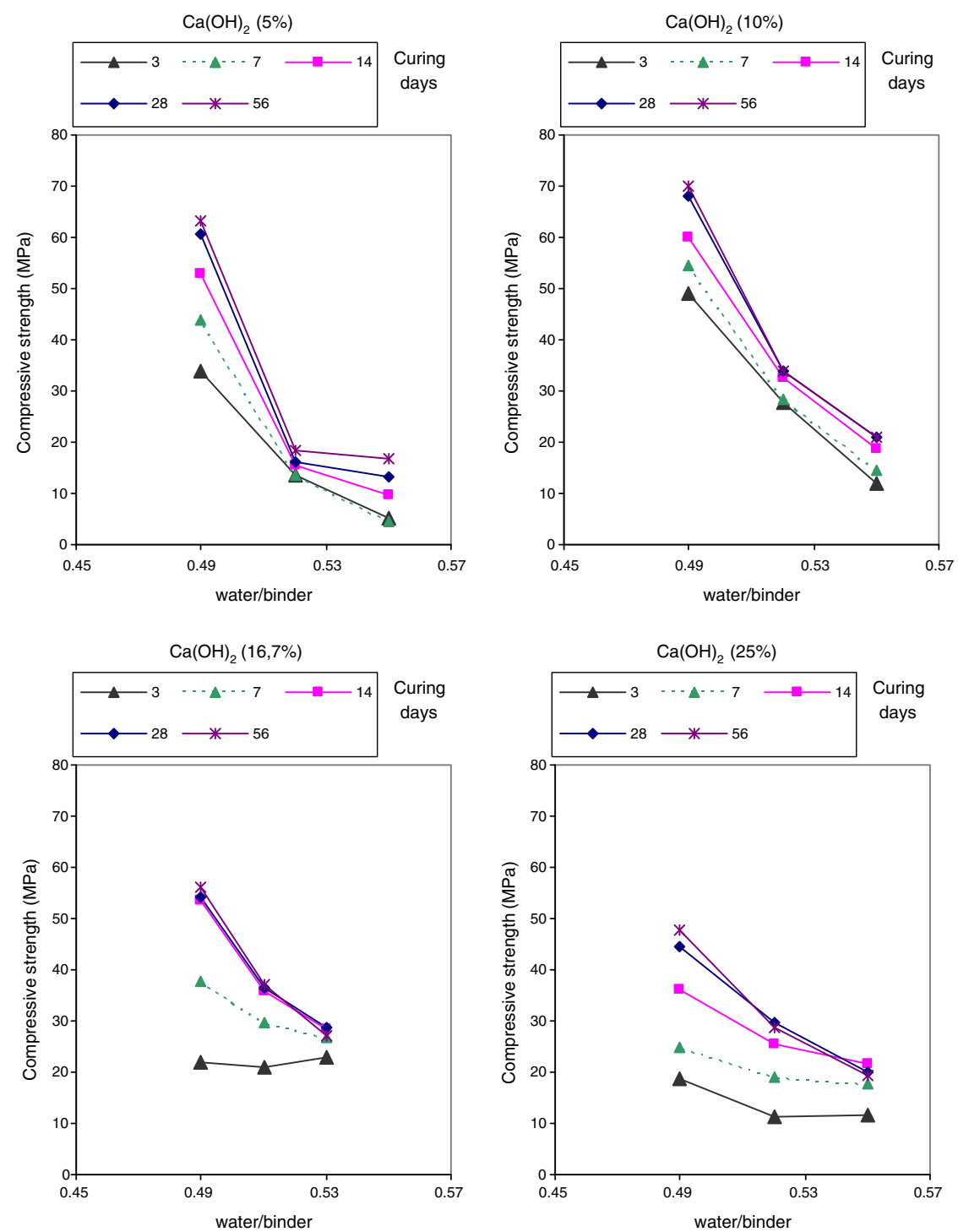

Fig. 6. Compressive strength versus water/binder mass ratio for several calcium hydroxide percentages (5\%, 10\%, 16,7\% and 25\%). 
The use of $16.7 \%$ and $25 \%$ calcium hydroxide percentages, although associated with a strength rise due to the use of a $24 \mathrm{M}$ concentration, achieved a far lower strength than the 10\% calcium hydroxide percentage. This behaviour can be explained by the use of less aluminosilicate mine waste (replaced by calcium hydroxide) as well by the increase of unreacted particles, due to less setting time, because calcium hydroxide shortens setting time. As for the water/binder ratio (Fig. 6), strength results show that for mixtures with $16.7 \%$ and $25 \%$ calcium hydroxide percentages it has some influence but only for long curing ages. For the mixtures with a $10 \%$ calcium hydroxide percentage, compressive strength has a linear relationship with the water/binder mass ratio, which is almost the same until the 56th curing day. As for the mixtures with a 5\% calcium hydroxide percentage, strength is only influenced by the water/binder mass ratio only below 0.52 . Since the strength behaviour is related to the $\mathrm{H}_{2} \mathrm{O} / \mathrm{Na}_{2} \mathrm{O}$ molar ratio, they cannot be explained per se, unless the comparison was made between mixtures with the same ratio.

As for the sodium/binder percentage ratio (percentage of sodium mass over binder mass), it can be seen (Fig. 7) that when the parameter increases compressive strength also increases. Lower percentages of calcium hydroxide show to be more influenced than when $16,7 \%$ and $25 \%$ calcium hydroxide percentages were used at early ages. The explanation for this behaviour could be due to the nature of the reaction products formed which are influenced by calcium hydroxide solubility in high alkaline environment. The use of a sodium/binder percentage of $17 \%$ is higher than the percentages reported in the current literature. This maybe due to the low Blaine fineness of mine waste mud $\left(3570 \mathrm{~cm}^{2} / \mathrm{g}\right)$ which needs a higher sodium concentration to increase dissolution.

As for the $\mathrm{H}_{2} \mathrm{O} / \mathrm{Na}_{2} \mathrm{O}$ molar ratio (Fig. 8), the strength results show that the use of low water/sodium ratios is
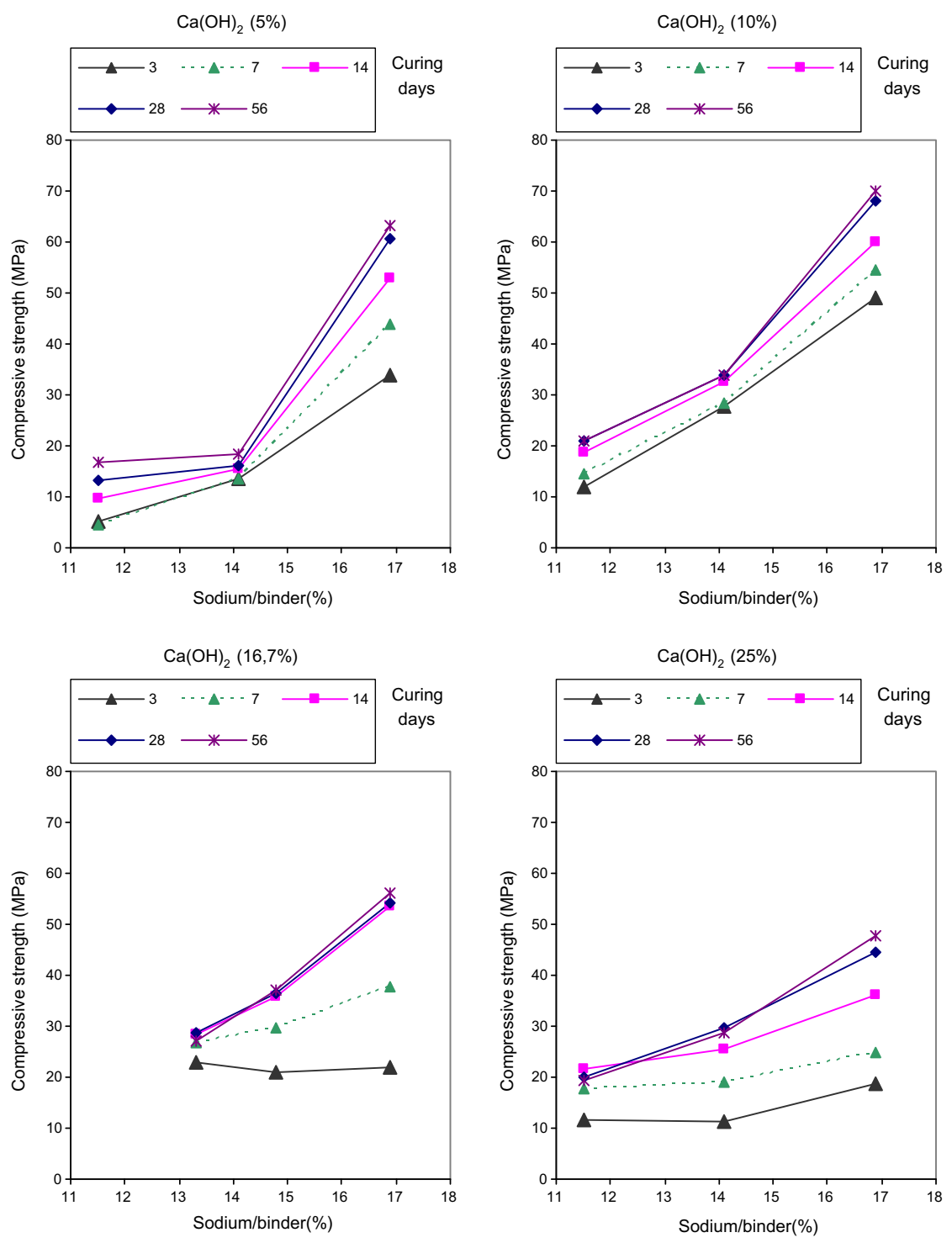

Fig. 7. Compressive strength versus sodium/binder percentage for several calcium hydroxide percentages $(5 \%, 10 \%, 16,7 \%$ and $25 \%)$. 

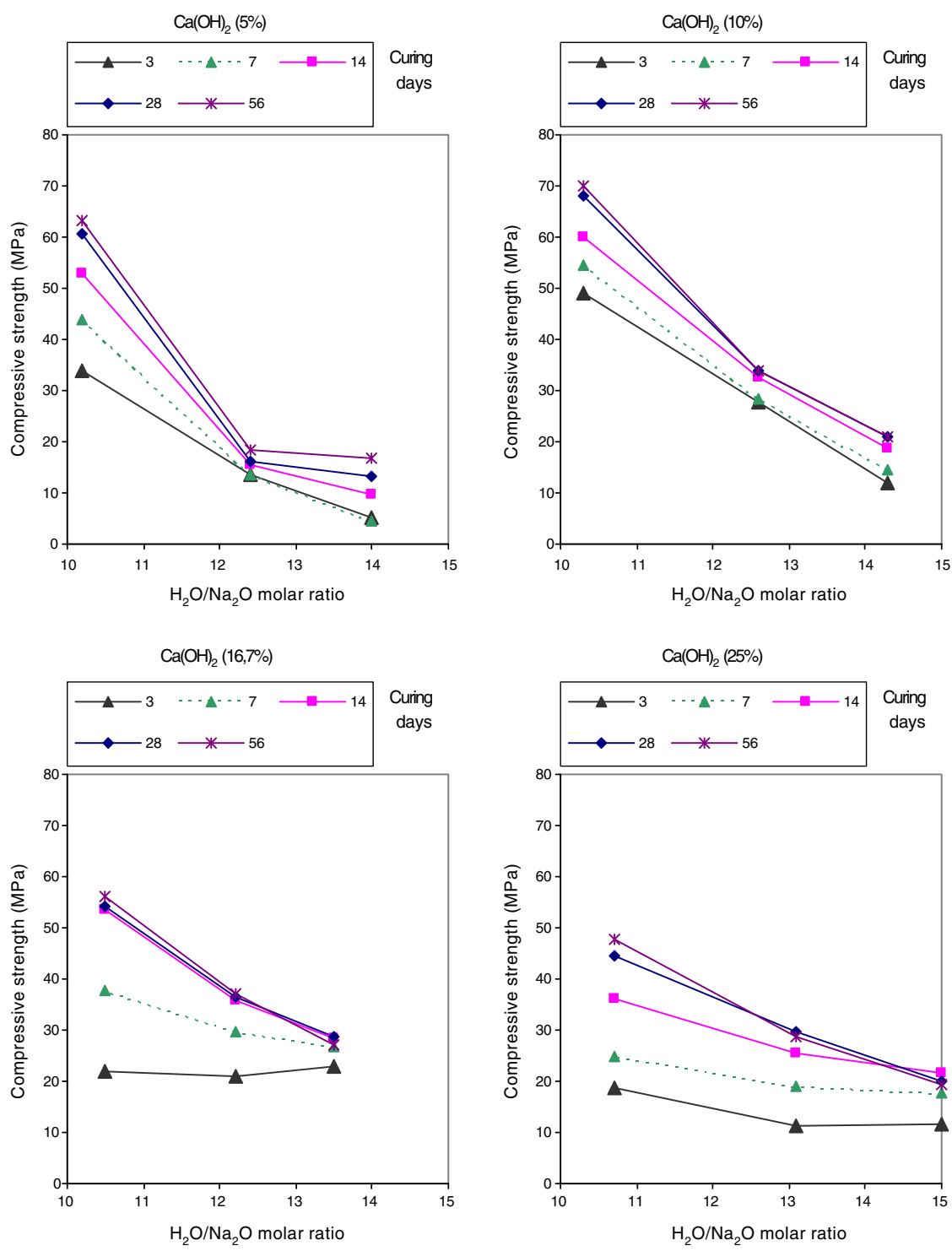

Fig. 8. Compressive strength versus $\mathrm{H}_{2} \mathrm{O} / \mathrm{Na}_{2} \mathrm{O}$ molar ratio for several calcium hydroxide percentages $(5 \%, 10 \%, 16.7 \%$ and $25 \%$ ).

crucial for achieving high strength performances, below 12.5 for low calcium hydroxide percentages. For $\mathrm{H}_{2} \mathrm{O}$ / $\mathrm{Na}_{2} \mathrm{O}$ molar ratios below 10 , higher strength performance could even be expected. This, however, implies more extra water reductions, or even the use of lower activator/binder ratios, which may lead to workability problems.

\section{Conclusions}

The strength data for long curing ages show that the parameters, which lead to optimum strength for 7 days curing, remain the same, however, when calcium hydroxide percentages above $10 \%$ are used, a relevant strength decrease after 14th curing day is noticed. In order to explain this behaviour several hypotheses are analyzed: the possibility of the geopolymeric reaction and the CSH reaction compete for soluble silicates, leading to a more porous and less strength phase; the possibility of shrinkage crack occurrence near the aggregates or the formation of alkali-silica gel similar to the one that takes place in ASR. The use of mixtures with a waterglass/sodium hydroxide above 3:1 could not even be properly mixed due to the viscosity of waterglass.

The use of an activator with a sodium hydroxide concentration of $24 \mathrm{M}$ leads to very high compressive strengths, for early ages with $30 \mathrm{MPa}$ after just 1 day as well as after just 28 days $(70 \mathrm{MPa})$. The highest compressive strength is obtained with a mixture containing $10 \%$ of calcium hydroxide. The use of a $5 \%$ calcium hydroxide percentage, gives rise to much lower strength after just one day but has almost the same strength performance after 28 days curing. The strength performance is typical of a very reactive binder, being suggested that it is due to the calcium hydroxide and also to the nucleation centers provided by the iron oxide of the mine waste mud. Results allow foreseeing that even higher strength performance could be achieved if lower water/sodium molar ratios were used. 


\section{References}

[1] UNFCCC-Kyoto Protocol to the United Nations framework convention on climate change, United Nations convention on climate change, FCC/CP/L.7/Add1, Kyoto.

[2] European Environmental Agency - Greenhouse gas emission trends and projections in Europe 2004. EEA Technical Report No. 5/2004.

[3] Pacheco-Torgal F, Castro-Gomes JP, Jalali S. Geopolymeric based binder. An environmental alternative to Portland cement in the carbon economy context Concrete Magazine. Portuguese ReadyMixed Association; 2005, p. 37-46 [in Portuguese].

[4] Roy Della M. Alkali - activated cements. Opportunities and challenges. Cement Concrete Res 1999;29:249-54.

[5] Palomo A, Blanco-Varela MT, Granizo ML, Puertas F, Vasquez T, Grutzeck MW. Chemical stability of cementitious materials based on metakaolin. Cement Concrete Res 1999;29:997-1004.

[6] Bakharev T, Sanjayan JG, Cheng YB. Resistance of alkali-activated slag concrete to acid attack. Cement Concrete Res 2003;33:1607-11.

[7] Barbosa Valeria F, MacKenzie Kenneth J. Synthesis and thermal behaviour of potassium sialate geopolymers. Mater Lett 2003;57:1477-82.

[8] Balaguru P. Geopolymer for protective coating for transportation infrastructures. Center for Advanced Infrastructure and Transportation, Civil \& Environment Engineering Rutgers, The State University Piscataway. Final Report FHWA NJ; 1998, p.12.

[9] Jaarsveld JGS, Deventer JSJ, Lorenzen L. The potential use of geopolymeric materials to immobilise toxic metals: Part I. Theory and Applications. Miner Eng 1997;10:659-69.
[10] Jaarsveld JGS, Deventer JSJ, Schwartzman A. The potential use of geopolymeric materials to immobilise toxic metals: Part II. Material and leaching characteristics. Miner Eng 1999;12:75-91.

[11] Hermann E, Kunze C, Gatzweiler R, Kiebig G, Davidovits J. Solidification of various radioactive residues by geopolymere with special emphasis on long term stability. In: Proceedings of 1999 geopolymere conference.

[12] Palomo A, Grutzec MW, Blanco MT. Alkali - activated fly ashes. A cement for the future. Cement Concrete Res 1999;29:1323-9.

[13] Xu Hua, Deventer JSJ. The geopolymerisation of alumino-silicate minerals. Int J Miner Process 2000;59:247-66.

[14] Pacheco-Torgal F, Castro-Gomes JP, Jalali S. Geopolymeric binder using tungsten mine waste: preliminary investigation. In: Proceedings of geopolymer 2005 world congress. Saint Quentin,. France; 2005. p. 93-98.

[15] Pacheco-Torgal F, Castro-Gomes JP, Jalali S. Effect of mix design on the early age strength of alkali-activated mine waste mud mortars. Constr Build Mater [in press].

[16] Pacheco-Torgal F, Castro-Gomes JP, Jalali S. Thermal treatment of waste mud from Panasqueira mine. Influence of time and temperature calcination. In: Engineering conference 2005. University of Beira Interior. Covilhã, Portugal [in Portuguese].

[17] Yip CK, Lukey GC, Deventer SJS. The coexistence of geopolymeric gel and calcium silicate hydrate gel at the early stage of alkaline activation. Cement Concrete Res 2005.

[18] Lee WKW, Van Deventer JSJ. The effects of inorganic salt contamination on the strength and durability of geopolymers. Colloid Surface 2002;211:115-26. 